\title{
BIOPHARMACEUTICAL AND MARKETING EVALUATION OF DIOSMIN- AND HESPERIDIN-CONTAINING PRODUCTS ON THE BULGARIAN MARKET
}

\author{
Nadezhda Ivanova ${ }^{1}$, Yozlem Hyusein ${ }^{2}$, Iliya Slavov ${ }^{3}$, Ivo Kumanov ${ }^{4}$ \\ ${ }^{1}$ Department of Pharmaceutical Technologies, Faculty of Pharmacy, \\ Medical University of Varna \\ ${ }^{2}$ Student, Faculty of Pharmacy, Medical University of Varna \\ ${ }^{3}$ Department of Biology, Faculty of Pharmacy, Medical University of Varna \\ ${ }^{4}$ Department of Organization and Economics of Pharmacy, Faculty of Pharmacy, \\ Medical University of Varna
}

\begin{abstract}
INTRODUCTION: Diosmin and hesperidin are commonly used flavonoids in the therapy of vascular diseases.

AIM: This study aimed to present an independent evaluation of the market status, quality and biopharmaceutical characteristics of diosmin- and hesperidin-containing oral tablet-products (DHCPs) on the Bulgarian market.

MATERIALS AND METHODS: Seven products, among which medicines (used as reference) and food supplements, with sustainable or growing market were selected for the survey: Detralex $\mathbf{5 0 0}$ mg, Phlebodia $600 \mathrm{mg}$, Dioket $600 \mathrm{mg}$, Novarix $650 \mathrm{mg}$, Asketon $500 \mathrm{mg}$, Venocode and Dih max $1000 \mathrm{mg}$. Sales analysis for 2016, 2017 and 2018 (year-to-date) was done with the kind support of Iqvia TM. All products were subjected to European Pharmacopoeia (EP) tests for tablet quality - disintegration, resistance to crushing, uniformity of mass and uniformity of dosage units. Biopharmaceutical profile regarding tablet drug release and dissolution potency was investigated on EP Apparatus 2 (Paddle method).

RESULTS: Although all products were found to almost fully fulfill the EP criteria, extremely unsatisfying drug release was established in all tested media $(\mathrm{pH} 1,5, \mathrm{pH} 4,5$ and $\mathrm{pH} 7,2)$, reaching not more than $1.6 \%$ of the labeled content after 24 hours for the best performing products - Novarix and Venocode.

CONCLUSION: These results were not surprising considering diosmin and hesperidin's water insolubility and respective low bioavailability. However, it would be reasonable to approach these two bioactive compounds technologically in preformulation stage in order to improve their solubility and therapeutic potency.
\end{abstract}

Keywords: diosmin, hesperidin, medicines, food supplements, tablets quality, drug release

Address for correspondence:

Nadezhda Ivanova

Faculty of Pharmacy

Medical University of Varna

84 Tzar Osvoboditel Blvd

9002 Varna

e-mail:nadejda__iv@abv.bg

Received: November 27, 2018

Accepted: December 21, 2018

Scripta Scientifica Pharmaceutica, 2018;5(2):61-70 


\section{INTRODUCTION}

\section{Structure, Sources and Isolation}

Diosmin and hesperidin are flavonoids widely used in the treatment of diseases of microcirculatory and vascular origin such as venous insufficiency, varicose veins, hemorrhoids, edemas, post-operative conditions, etc. Both the flavon (Fig. 1A) and the flavanon glycoside (Fig. 1B) possess vasoprotective and venotonic properties (1-14). Diosmin differs from hesperidin by a double bond present in the structure of the former between $\mathrm{C}_{2}$ and $\mathrm{C}_{3}$ (Fig. 1) (1-3). Although both glycosides are naturally occurring in the families of Rutaceae, Lamiaceae, Apiaceae, Scrophulariaceae (S. nadosa) (2-10), the industrial sector uses semisynthetic diosmin derived from hesperidin by a suitable oxidation reaction $\left(\mathrm{I}_{2} /\right.$ pyridine, $\mathrm{I}_{2} /$ dimethylsulfoxide or other) (1-3,11,15-18). Hesperidin is most commonly isolated from dry orange or citrus peels (Citrus sinesis, L., Citrus aurantium, L., Citrus lemon, L., and other Citrus species) $(3,8,10)$.

\section{Characteristics}

The substances appear as greyish-yellow or light yellow hygroscopic powders. They are practically insoluble in water and alcohol, soluble in dimethyl sulfoxide and dilute solutions of alkali hydroxides $(2,19)$.

\section{Pharmacokinetics}

In vivo diosmin and hesperidin are absorbed through their aglycone forms - diosmetin and hesperetin, respectively, which are products of the intestinal flora-mediated metabolism $(1,2,7,9,12,13)$. However, the latter are not proven to be active metabolites, as they arise due to biotransformation in the gastro-intestinal tract (GIT), but once absorbed, further on undergo glucuronidation and biodegradation to fenolic derivatives, while unmetabolized forms are not found in plasma $(7,9,12)$. For main metabolites are deemed the 3-O-Glucoronide, 7-O-Glucoronides and 3,7-O-Glucoronide conjugates of the aglycoons $(2,7,12,13)$. Generally, diosmin and hesperidin undergo urine excretion $(1,2,7,9,12)$. The biological half-life $\left(\mathrm{t}_{1 / 2}\right)$ of diosmetin (or more particularly its conjugated forms) is estimated to be 26-43 hours (1). Unabsorbed diosmin and hesperidin are eliminated with the feces $(1,2)$.

\section{Pharmacodynamics}

Several mechanisms of action are suggested to be responsible for the beneficial effects of the com-

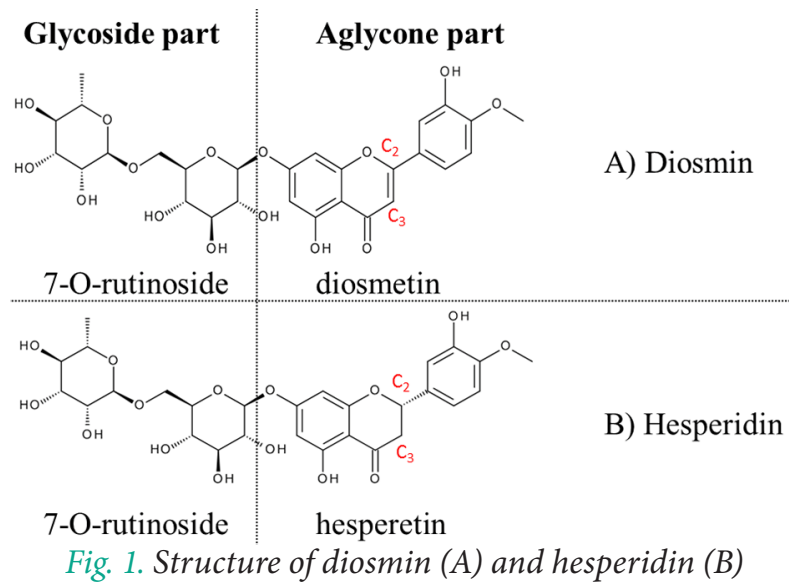

pounds on the vascular system. First, as flavonoid representatives, they possess a so-called vitamin Paction, manifesting in decrease in vascular permeability and increase in capillary sustainability and elasticity $(6,8,11)$. The aforementioned effects are hypothesized to be due to interference with catecholamine's metabolism. The flavonoids prolong the extraneuronal presence of noradrenaline and its vasoconstrictive action by inhibition of the catechol-Omethyl transferase (COMT-enzyme) and by binding the free plasma ferric and copper ions in inactive chelate complexes (the ions in question are catalyzers of catecholamine's oxidation) (20). Another theory devotes the P-vitamin action to an inhibitory activity on the hyaluronidase family of enzymes, which are responsible for the degradation of hyaluronic acid. This extracellular constituent is essential for vascular health for it is known to strengthen the vascular walls by decreasing their permeability (21). Next, diosmin and hesperidin have an anti-inflammatory effect on the vessels due to prostaglandin E2 (PGE2), thromboxane A2 (TxA2) and leukocyte activation, migration and adhesion inhibitory activity $(1,2,4,6,11,14,22)$. The flavonoids also exhibit antioxidant properties owing to their ability to inhibit the NO-oxide synthase and block free-radical chain reactions. This quality of theirs favors the vessels' lumen condition through an antiatherogenic mechanism $(1,2,4,5,9,14,22)$. Last, both flavonoids have shown angiotensin-converting enzyme (ACE) inhibitory activity, hence they reduce pressure in circulation and this way additionally facilitate the healing of vascular-related diseases and complications (23). Diosmin and hesperidin are proven to possess 
Nadezhda Ivanova, Yozlem Hyusein, Iliya Slavov et al.

also other effects, unrelated to their vasoactive properties, such as antineoplastic, antiviral and antifungal $(1,24,25)$.

\section{Biopharmaceutical Properties}

In order to materialize all these desirable effects in patients though, diosmin and hesperidin need to be bioavailable after oral administration. This is crucial consideration when it comes to these particular drugs. Both compounds belong to class IV of the Biopharmaceutical Classification System (BCS) and thus possess low water solubility and low permeability $(2,3,7-9,14,19,26)$. While the low permeation rate is not so critical since the glycosides (if dissolved!) degrade to easily absorbable aglycons (diosmetin and hesperetin), their water insolubility is a highly limiting factor for pharmaceutical availability, systemic absorption and oral bioavailability. Therefore, the dosage form formulation, including substance processing, adjuvants, type of carrier system, technological operations etc., has major role in achieving optimized therapeutic response. In this regard, the use of diosmin and hesperidin in micronized fraction appears to be indispensable for their potency as pharmaceuticals $(3,7-9,14)$. The smaller-sized particles benefit the solubility rate of slightly soluble and practically insoluble drugs by enlarging their surface area with the dissolvent. However, as mentioned before, many other technological factors are to be considered for high pharmaceutical availability.

\section{AIM}

The present study aims to compare the quality and biopharmaceutical properties of diosmin- and hesperidin-containing (or diosmin alone) oral tablet products (DHCPs), at the same time making a parallel with their market shares in Bulgaria for the past 3 years. In the last years, the majority of new competing DHCPs manufacturers register food supplements rather than medicines out of regulatory and convenience considerations. As a result, alternatives to the conventionally adopted combination of 450 $\mathrm{mg}$ diosmin+50 $\mathrm{mg}$ hesperidin or $600 \mathrm{mg}$ diosmin tablets, being new combinations with other natural vasoprotectors (collagen, hyaluronic acid, escin etc.) or new drug concentrations, multiply relatively fast. At the same time, medicines as Detralex (450 mg diosmin+50 mg hesperidin) and Phlebodia (600 mg diosmin) keep holding the major market share on $\mathrm{DH}$ -
CPs in Bulgaria as a consequence of their affirmed long-standing presence and quality by default (for they are a subject of medicine regulation unlike food supplements). It is a question, even among the medical and pharmaceutical society, whether all these alternatives on the market possess the same quality or somewhat excel the potency of the referent products. In sake of objectivity, it is worth mentioning that the flavonoids in question are primarily subject of medical prescription in Europe, but at the same time provided mostly as food supplements on the US market (12).

Before proceeding to the experimental part exhibition, we would like to emphasize that our assessment was based entirely on in vitro methods and prognoses. It does not concern the potential benefits of additional active ingredients in tablets in vivo (as hyaluronic acid, escin, collagen, etc.) and regards only diosmin/hesperidin content, properties and release behavior as well as tablet quality.

\section{MATERIALS}

Hesperidin standard 97\% was purchased from Acros Organics Belgium, diosmin:hesperidin 9:1 commercial mixture micronized (DHM9:1) was purchased from Shaanxi Pioneer Biotech Co., Ltd., China, sodium hydroxide, di-sodium hydrogen phosphate, potassium dihydrogen phosphate, sodium chloride were purchased from Thermo Fisher Scientific, $0.22 \mu \mathrm{m}$ pore size PES syringe filter - from Filters Fioroni, Spain.

\section{METHODS}

\section{Marketing Analysis}

Sales analysis for all products (2016-2018year to date (YTD)) was performed with the aid of Iqvia ${ }^{\mathrm{TM}}$ data base. The sales in packages and BGN (summarized for all product variations - for example 30 tablets package +60 tablets package +90 tablets package) were presented on pie charts.

\section{Analytical Method}

Diosmin and hesperidin determination was performed by UV spectrophotometric method on Thermo Scientific Evolution 220 UV/Vis Spectrophotometer. Spectra of DHM9:1 and hesperidin standard were scanned in $0.25 \mathrm{M} \mathrm{NaOH}$ solutions. Absorption maxima were found at $267 \mathrm{~nm}$ for DHM9:1 and at $283 \mathrm{~nm}$ for pure hesperidin (Fig. 2A 
and B). Standard calibration curves of DHM9:1 and hesperidin were built in $0.25 \mathrm{M} \mathrm{NaOH}$ in concentration range of $1-50 \mathrm{mg} / \mathrm{L}$, for each at both wavelengths (WL) in order to establish: 1) whether the presence of hesperidin will affect linearity for diosmin at $267 \mathrm{~nm}$ when in mixture 9:1;2) whether the standard solutions of hesperidin will show reliable linearity in absorbability at $267 \mathrm{~nm}$, even if the absorption maxima of the compound is found at $283 \mathrm{~nm} ; 3$ ) accordingly, whether diosmin and hesperidin can be determined simultaneously in mixture 9:1 at $267 \mathrm{~nm}$ via this method, and 4) what would the absorptivity and linearity of diosmin alone at $267 \mathrm{~nm}$ be, considering the standard curve of DHM9:1 and hesperidin at the same WL. Detailed information about standard solutions, concentrations and resulting calibration curves is presented in Table 1 and Figure 3.

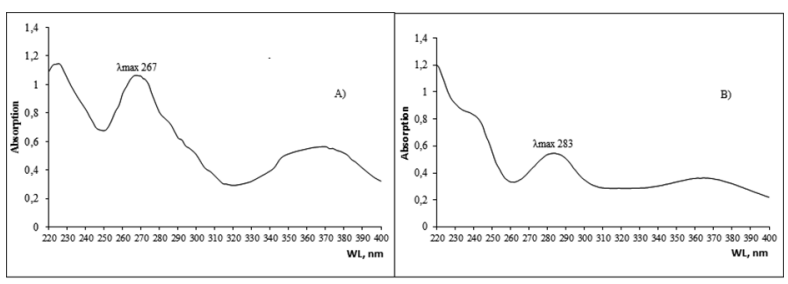

Fig. 2. UV spectra of DHM9:1 (A) and hesperidin (B) in $0.25 \mathrm{MNaOH}$ solution at concentration $25 \mu \mathrm{g} / \mathrm{mL}$
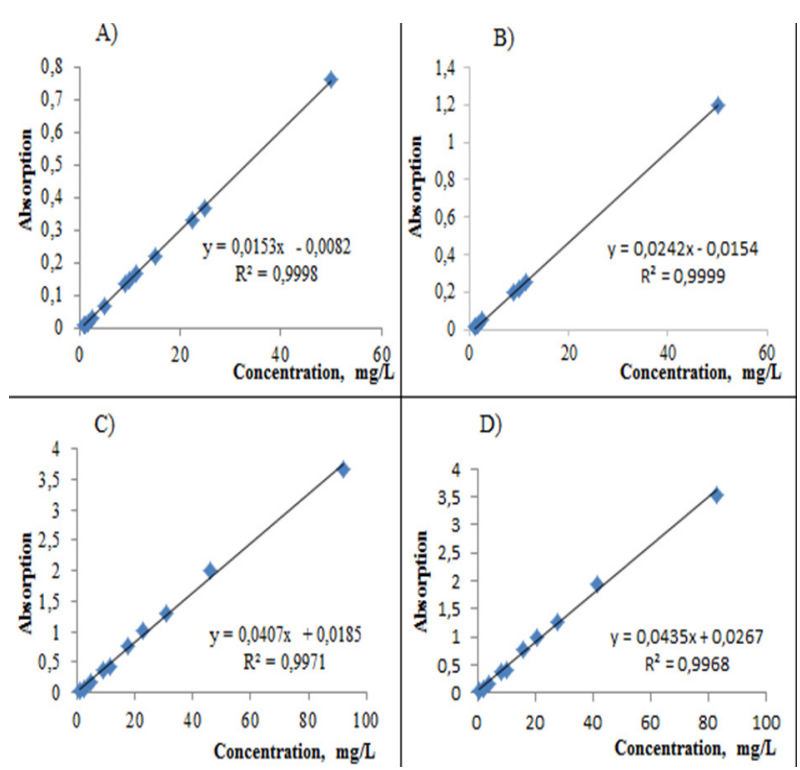

Fig. 3. Standard calibration curves of hesperidin at 267 $\mathrm{nm}$ (A), of hesperidin at $283 \mathrm{~nm}(\mathrm{~B})$, of DHM9:1 at 267 $\mathrm{nm}(\mathrm{C})$ and diosmin at $267 \mathrm{~nm}(\mathrm{D})$

The aforementioned method was found to be suitable for simultaneous determination of diosmin and hesperidin for it shows good linearity $\left(\mathrm{R}^{2}>0.997\right)$ and sufficient for the purpose of this study limit of detection (LOD).

Table 1. Standard solutions of DHM91 and hesperidin standard in $\mathrm{NaOH} 0.25 \mathrm{M}$

\begin{tabular}{l|ccc}
$\begin{array}{l}\text { Standard solutions of } \\
\text { Hesperidin, mg/L }\end{array}$ & $\begin{array}{c}\text { Concentration of } \\
\text { Diosmin in standard } \\
\text { solutions of DHM9:1, } \\
\text { mg/L }\end{array}$ & $\begin{array}{c}\text { Concentration of } \\
\text { Hesperidin in standard } \\
\text { solutions of DHM9:1, } \\
\text { mg/L }\end{array}$ \\
$\mathbf{1 . 0 0}$ & $\mathbf{1 . 0 0}$ & 0.90 & 0.10 \\
$\mathbf{1 . 2 5}$ & $\mathbf{1 . 2 5}$ & 1.13 & 0.13 \\
$\mathbf{1 . 6 7}$ & $\mathbf{1 . 6 7}$ & 1.50 & 0.17 \\
$\mathbf{2 . 5 0}$ & $\mathbf{2 . 5 0}$ & 2.25 & 0.25 \\
$\mathbf{5 . 0 0}$ & $\mathbf{5 . 0 0}$ & 4.50 & 0.50 \\
$\mathbf{9 . 0 0}$ & $\mathbf{1 0 . 0 0}$ & 9.00 & 1.00 \\
$\mathbf{1 0 . 0 0}$ & $\mathbf{1 2 . 5 0}$ & 11.25 & 1.25 \\
$\mathbf{1 1 . 2 5}$ & $\mathbf{2 0 . 0 0}$ & 18.00 & 2.00 \\
$\mathbf{1 5 . 0 0}$ & $\mathbf{2 5 . 0 0}$ & 22.50 & 2.50 \\
$\mathbf{2 2 . 5 0}$ & $\mathbf{3 3 . 3 3}$ & 30.00 & 3.33 \\
$\mathbf{2 5 . 0 0}$ & $\mathbf{5 0 . 0 0}$ & 45.00 & 5.00 \\
$\mathbf{5 0 . 0 0}$ & $\mathbf{1 0 0 . 0 0}$ & 90.00 & 10.00 \\
\hline
\end{tabular}


Nadezhda Ivanova, Yozlem Hyusein, Iliya Slavov et al.

\section{EUROPEAN PHARMACOPOEIA TESTS FOR TABLETS \\ Uniformity of Mass}

Twenty tablets of each DHCP were individually weighed on analytical balance. Average mass and standard deviation (SD) were determined. Method

Uniformity of Dosage Units - Mass Variation

According to the EP recommendations, the test for uniformity of dosage units for film-coated tablets (as all tested DHCPs are) was carried out by the mass variation method (19). Ten tablets were weighed and examined for active substance content. Each tablet was pulverized and dispersed in sufficient quantity of $0.25 \mathrm{M} \mathrm{NaOH}$ solution. The resulting slurry was transferred to a $50 \mathrm{~mL}$ volumetric flask and diluted up to the mark with $0.25 \mathrm{M} \mathrm{NaOH}$. After effective homogenization of the mixture, a sample was withdrawn, filtrated $(0.22 \mu \mathrm{m}$ pore size PES syringe filter), properly diluted and analyzed spectrophotometrically for drug content. Based on the results, acceptance value (AV) was calculated (19).

\section{Resistance to Crushing}

Resistance to crushing of tablets was performed on Erweka Tablet Hardness tester (125 series). Ten tablets of each product were subjected to the test. Average hardness was calculated.

\section{Disintegration}

Disintegration test for film-coated tablets was performed on EP Apparatus A (Erweka Disintegration tester ZT 220 series). Six tablets of each product were subjected to the test in preliminary heated at $37 \pm 2{ }^{\circ} \mathrm{C}$ distilled water. Disintegration time was determined as the time needed for all six tablets to disintegrate completely.

\section{In Vitro Dissolution Study \\ Solubility Study}

Prior to the study, test for solubility of DHM9:1 in all selected release media (hydrochloric acid solu-

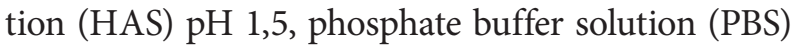
$\mathrm{pH} 4,5$ and $\mathrm{PBS} \mathrm{pH} 7,2)$ was carried out. The substance was added in excess to each solution and left under continuous stirring for 24 hours in a tempered room $\left(25^{\circ} \mathrm{C}\right)$. At the end of the study, sample from the supernatant was withdrawn, filtered and analyzed for drug concentration. The measured concentration was perceived as saturation point for DHM9:1 in the given solvent under the above described conditions.

In regard to the substances poor water solubility and related problematics in ensuring "sink” conditions during test, (dissolution test) was performed by two methods - Method I (Standard): on EP Apparatus 2 - Paddle method (Pharma test dissolution tester PT-DT70), and Method II: on flow-through cell resembling setting (Fig. 4). The parameters of the studies are presented in Table 2.

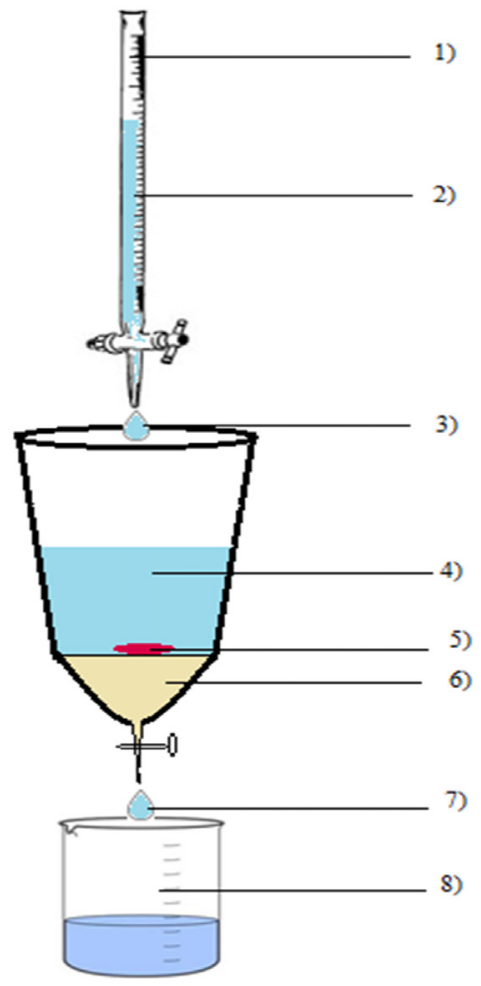

Fig. 4. Flow-through cell resembling setting (Method II applied for dissolution study): 1. Burette; 2. Pre-heated buffer solution $\left(37^{\circ} \mathrm{C}\right) ; 3$. Dripping of buffer solution into a percolator, containing the dosage form (flow-in); 4. Percolator, used as release chamber (kept with constant volume of buffer solution - $50 \mathrm{~mL}$ ); 5. Test dosage form; 6 . Filter; 7. Dripping of buffer solution enriched in diosmin and hesperidin out of the release chamber into a receiving compartment (flow-out); 8. Receiving compartment

\section{RESULTS AND DISCUSSION}

In this section, we present the results using a code name for each product (Product A, B, C etc.), in order to avoid conflict of interests. Where the prod- 
Table 2. In vitro drug release tests - parameters of the studies

\begin{tabular}{|c|c|c|c|c|c|c|c|c|c|}
\hline Method & $\begin{array}{l}\text { Type of } \\
\text { system }\end{array}$ & $\begin{array}{l}\text { Sink } \\
\text { condi- } \\
\text { tiones }\end{array}$ & Time & Release media & $\begin{array}{c}\text { Volume, } \\
\mathrm{mL}\end{array}$ & $\begin{array}{l}\text { Rotation } \\
\text { speed, } \\
\text { rpm }\end{array}$ & $\begin{array}{l}\text { Tempera- } \\
\text { ture, }{ }^{\circ} \mathrm{C} \quad \text { speed }\end{array}$ & $\begin{array}{l}\text { Flow- } \\
\text { out } \\
\text { speed }\end{array}$ & $\begin{array}{l}\text { Sampling and mesure- } \\
\text { ment }\end{array}$ \\
\hline
\end{tabular}

$0-1 \mathrm{~h} \quad \mathrm{HAS} \mathrm{pH} 1,5 \quad 900$

I. EP Ap-

paratus

method

(Method I)

$$
\text { 1-4h PBS pH 4,5 } 900
$$

2: Paddle closed no

100

$37 \pm 0.5$

$\mathrm{x}$

$\mathrm{x}$

II. Flowthrough cell resambling setting (Method II) 0-1h HAS pH $1,5 \quad 50$

\section{4-24h PBS pH 7,2 900}

$\begin{array}{llll}\begin{array}{c}\text { ope- } \\ \text { ned }\end{array} \text { yes } & & & \\ & & & \end{array}$

4-12h PBS pH 7,2 50
Samples from the release media were withdrawn at chosen times (through $5 \mu \mathrm{m}$ pore size filter) and analyzed spectrophotometrically for diosmin and hesperidin content. Concentration $[\mathrm{mg} / \mathrm{L}]$ was extrapolated to [mg] drug released in $900 \mathrm{~mL}$ and \% drug released was presented knowing the labeled drug content in tablets.

The buffer solution, collected in the receiving compartiment, was analyzed for diosmin and hesperidin content at chosen times. Drug concentration $[\mathrm{mg} / \mathrm{L}]$ was extrapolated to \% drug released, knowing the exact volume of the collected buffer at the time of the measurement and the labeled drug content. uct is a medicine, index $[\mathrm{m}]$ will be found in the upper right corner of the initials.

\section{Sales Analysis}

Presented on Figure 5 is the sales analysis of products from A to G for 2016, 2017 and 2018 YTD. As can be seen from the figure, leaders of the market are all medicines, whereas the number and total share of the food supplements grow with each year, but still expectedly, separately they have much fewer sales. Another tendency to be noted is the increase in the total consumption of DHCPs.

\section{Quality of Tablets}

Results of the tests regarding tablet quality are summarized in Table 3. All tablets were found to comply with the EP criteria for uniformity of mass and to possess substantial hardness above $200 \mathrm{~N}$. Even though there are no referent values in EP for the latter parameter, the hardness of a tablet should provide sustainability, at the same time not affecting negatively its disintegration. Since no producer has declared the product to possess modified release properties, we accepted $\leq 30$ minutes as reference value for disintegration. Tablets of all products were found to disintegrate within 30 minutes, except product B - 73 minutes. This observation we attribute to the lack of superdisintegrants in the composition of Product $\mathrm{B}$, as well as to the excessive hardness of the tablet $(>300 \mathrm{~N})$. However, knowing the poor water solubility of diosmin and hesperidin, slower disintegration is highly unlikely to play a crucial role in the in vivo performance of the products. Calculation of AV for uniformity of dosage units showed one critical value for Product $B$ and one drastically above the EP criteria value (Product C). 
Sales 2016 in packages

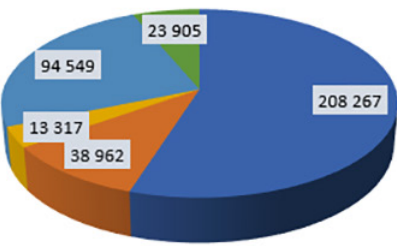

$\square$ Product Am $\|$ Product $\mathrm{B} \quad \square$ Product $\mathrm{C} \|$ Product $\mathrm{D}$

a Product $\mathrm{Em}$ in Product $\mathrm{Fm}$ = Product $\mathrm{G}$

\section{Sales 2016 in BGN}

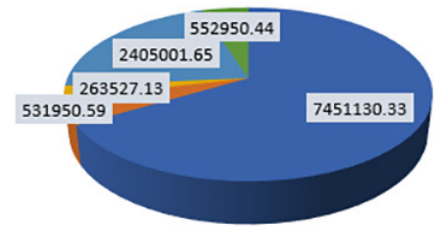

Product $\mathrm{Am} \|$ Product $\mathrm{B} \|$ Product $\mathrm{C} \|$ Product $\mathrm{D}$

a Product Em $\|$ Product Fm 1 Product 6

Sales 2017 in packages

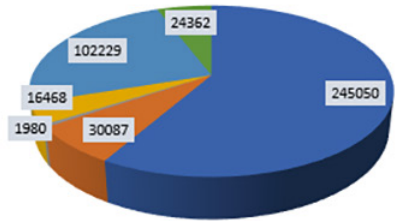

- Product Am $\|$ Product $B \quad \equiv$ Product $C=$ Product $D$

= Product $\mathrm{Em}$ = Product $\mathrm{Fm} \equiv$ Product $\mathrm{G}$

Sales 2018 YTD in packages

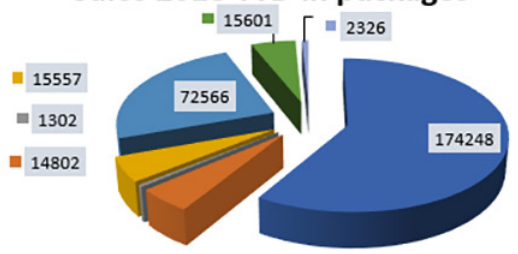

- Product Am $=$ Product B $\equiv$ Product $C \equiv$ Product D

= Product $\mathrm{Em} \|$ Product $\mathrm{Fm}=$ Product $\mathrm{G}$

\section{Sales 2017 in BGN}

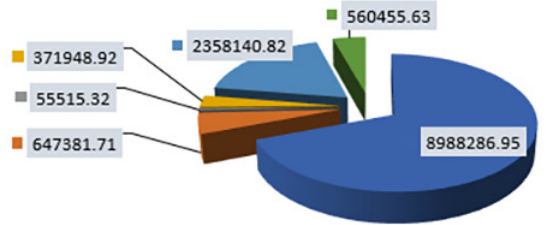

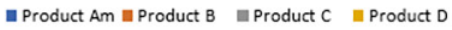

a Product $\mathrm{Em} \|$ Product $\mathrm{Fm} \|$ Product $\mathrm{G}$

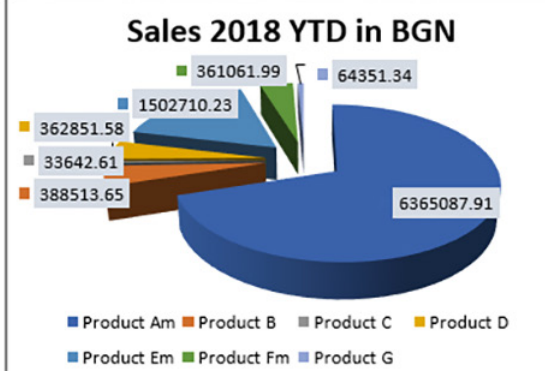

Fig. 5. Sales analysis of selected DHCPs for 2016-2018 YTD in packages and BGN

Table 3. Quality of tablets

\begin{tabular}{|c|c|c|c|c|c|c|c|c|c|c|c|}
\hline \multirow[b]{2}{*}{ PRODUCT } & \multicolumn{3}{|c|}{ UNIFORMITY OF MASS } & \multicolumn{4}{|c|}{ UNIFORMITY OF DOSAGE UNITS } & \multicolumn{2}{|c|}{$\begin{array}{l}\text { DISINTEGRA- } \\
\text { TION }\end{array}$} & \multicolumn{2}{|c|}{$\begin{array}{l}\text { RESISTANCE } \\
\text { TO CRUSHING }\end{array}$} \\
\hline & $\begin{array}{l}\text { Average } \\
\text { mass, mg }\end{array}$ & $\pm \mathrm{SD}^{\mathrm{a}}, \%$ & $\begin{array}{c}\text { EP Ac- } \\
\text { ceptance } \\
\text { criteria, } \\
\pm \text { SD } \%\end{array}$ & $\begin{array}{l}\text { Average } \\
\text { drug con- } \\
\text { tent, } \%^{\mathrm{b}}\end{array}$ & $\pm \mathrm{SD}, \%$ & $\begin{array}{l}\text { Acceptance } \\
\text { value }(\mathrm{AV})^{\mathrm{c}}\end{array}$ & $\begin{array}{c}\text { EP Ac- } \\
\text { ceptance } \\
\text { criteria, } \\
\text { AV }\end{array}$ & $\begin{array}{l}\text { Time, } \\
\min \end{array}$ & $\begin{array}{l}\text { EP Ac- } \\
\text { ceptance } \\
\text { criteria, } \\
\text { min }\end{array}$ & $\begin{array}{l}\text { Hardness, } \\
\mathrm{N}\end{array}$ & $\begin{array}{c} \pm \mathrm{SD} \\
\mathrm{N}\end{array}$ \\
\hline Product $A^{\mathrm{m}}$ & 688 & 0.65 & & 108.32 & 3.65 & 1.94 & & 17.56 & & 195 & 19 \\
\hline Product B & 848 & 0.53 & & 103.20 & 7.76 & 16.93 & & 73.00 & & $>300^{\mathrm{d}}$ & d \\
\hline Product C & 634 & 2.39 & & 99.05 & 12.16 & 31.64 & & 19.56 & & 218 & 13 \\
\hline Product D & 976 & 0.56 & $\leq 5.00$ & 109.01 & 4.90 & 4.24 & $\leq 15$ & 3.21 & $\leq 30$ & $>300^{\mathrm{d}}$ & $\mathrm{d}$ \\
\hline Product $E^{\mathrm{m}}$ & 944 & 0.58 & & 124.22 & 8.29 & -2.83 & & 10.20 & & 256 & 16 \\
\hline Product $\mathrm{F}^{\mathrm{m}}$ & 730 & 1.37 & & 109.99 & 8.88 & 12.82 & & 3.30 & & 189 & 24 \\
\hline Product G & 1278 & 0.65 & & 109.15 & 5.79 & 6.25 & & 3.22 & & $>300^{\mathrm{d}}$ & $\mathrm{d}$ \\
\hline
\end{tabular}

a SD - standard deviation

${ }^{\mathrm{b}}$ Drug content found in tablets, expressed as percent (\%) of the labeled content

${ }^{c} \mathrm{AV}$ was calculated according to the EP recommendations - chapter 2.9.40 Uniformity of dosage units, Mass variation

d The value of hardness $[\mathrm{N}]$ has excelled the apparatus limitations of detection (10-300 N), SD could not be calculated 


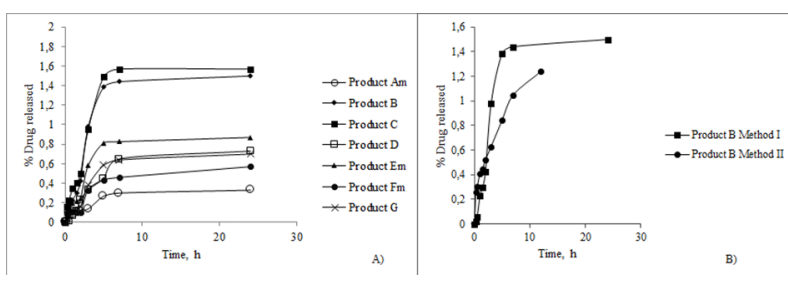

Figure 6. In vitro drug release of diosmin and hesperidin from all DHCPs obtained by Method I (A), comparison of release profiles of Product B obtained by Method I and II (B)

\section{Solubility}

In diosmin and hesperidin micronized powder 9:1 were found: saturate HAS $\mathrm{pH} 1,5$ at $897 \mu \mathrm{g} / \mathrm{L}, \mathrm{PBS}$ $\mathrm{pH} 4,5$ at $1462 \mu \mathrm{g} / \mathrm{L}$ and $\mathrm{PBS} \mathrm{pH} 7,2$ at $2125 \mu \mathrm{g} / \mathrm{L}$. According to the results obtained and the EP classification, DHM9:1 qualify as very slightly soluble in HAS pH 1,5 and slightly soluble in PBS pH 4,5 and pH 7,2.

Drug release profiles of tested DHCPs, obtained by Method I are presented on Fig. 6A. Very unsatisfying prognosis for pharmaceutical availability for all products was established, as the highest percent drug released reached no more than $1.6 \%$ of the labeled content (Product B and C). Fig. 6B on the other hand, demonstrates the significance of „sink” conditions for the drug release, by presenting the release profile of a randomly selected product (Product B) obtained by the two described methods - Method I (standard method, but „sink” requirements are not met according to the drug solubility test) and Method II (,sink” conditions are ensured). Comparison of both dissolution profiles of Product B showed differences in the rate constant of the dissolution process, but no substantial difference in the cumulated drug released after $12 \mathrm{~h}$; hence, the unsatisfying drug release of diosmin and hesperidin from the tablets cannot be attributed to the lack of „sink" conditioning in the classical closed dissolution tester system.

The results obtained in this study we perceive as informative in sake of comparison between the selected products. However, further in vivo studies of DHCPs and validation of analytical methods for determination of diosmin and hesperidin are needed to understand whether the extremely low pharmaceutical availability corresponds to just as low level of envisaged bioavailability. Authors researching this area seem to be unanimous about the challenging evalu- ation of diosmetin plasma concentrations due to the necessity of preliminary degradation of conjugated forms and precise definition of the latter. Therefore, the available pharmacokinetic data for diosmin is inconsistent and highly variable $(7,9,12)$. As the improvement of diosmin and hesperidin analysis is not a primary topic of our study, we rely on several recent pharmacokinetic reports to cross-check the credibility of our findings. For example, Russo et al. (2018) compare the pharmacokinetic profile of diosmin following oral administration of a $500 \mathrm{mg}$ single dose $\mu \operatorname{Smin}^{\otimes}$ (a diosmin flavonoid complex) (test) and unformulated micronized diosmin (reference). The maximum plasma concentrations $\left(\mathrm{C}_{\max }\right)$ detected by the authors are $50.3 \pm 22.6 \mathrm{ng} / \mathrm{mL}$ and $2.4 \pm 1.9$ $\mathrm{ng} / \mathrm{mL}$, respectively (7). Assuming the average plasma volume of an adult patient to be $2.75 \mathrm{~L}$, these plasma levels represent $0.06 \%$ and $0.003 \%$ of the initial dose administered (500 $\mathrm{mg}$ diosmin correspond to $246.8 \mathrm{mg}$ aglycone diosmetin). Another study, performed by Silvestro et al. (2013), shows $\mathrm{C}_{\max }$ of diosmetin following oral intake of $450 \mathrm{mg}$ diosmin to be $6049.3 \pm 5548.6 \mathrm{pg} / \mathrm{mL}$ (12). Under the same assumptions, this $\mathrm{C}_{\max }$ represents $0.0075 \%$ of the initial dose administered (450 $\mathrm{mg}$ diosmin correspond to 222 mg diosmetin). In comparison, the predicted values for pharmaceutical availability in our study vary between $0.33-1.57 \%$ among the products. Certainly, low pharmaceutical availability is a key factor for low plasma concentration and low oral bioavailability.

\section{CONCLUSION}

The main problem with DHCPs appears to be the very low water solubility of the substances even in micronized fraction, leading to unsatisfying pharmaceutical availability $(<1.6 \%)$. The need exist of additional technological approaches to improve diosmin and hesperidin's in vitro and in vivo performance. Such achievement could potentially benefit the patients' therapy and reduce side effects, originating from the high dose of unabsorbed flavonoids (often manifesting as gastro-intestinal disorders). Furthermore, it would definitely have a positive economic impact. We hope to be able to present a successful step in this direction in a future report. 
Nadezhda Ivanova, Yozlem Hyusein, Iliya Slavov et al.

\section{REFERENCES}

1. Thorne Research, Inc. Monograph. Diosmin. Altern Med Rev. 2004;9(3):308-11.

2. Bogucka-Kocka A, Woźniak M, Feldo M, Kockic J, Szewczyk K. Diosmin-isolation techniques, determination in plant material and pharmaceutical formulations, and clinical use. Nat Prod Commun. 2013;8(4):545-50.

3. Szymański M, Młynarek D, Szymański A, Matławska I. Simultaneous Determination of diosmin and hesperidin in pharmaceuticals by RPLC using ionic liquids as mobile phase modifiers. Iran J Pharm Res. 2016;15(1):141-8.

4. Londoño-Londoño J, Lima VR de, Lara O, Gil A, Pasa TBC, Arango GJ, et al. Clean recovery of antioxidant flavonoids from citrus peel: Optimizing an aqueous ultrasound-assisted extraction method. Food Chem. 2010;119(1):81-7. doi: 10.1016/j. foodchem.2009.05.075.

5. El-Shafae AM, El-Domiaty MM. Improved LC methods for the determination of diosmin and/ or hesperidin in plant extracts and pharmaceutical formulations. J Pharm Biomed Anal. 2001;26(4):539-45.

6. Bunaciu AA, Udristioiu GE, Ruţă LL, Fleschin S, Aboul-Enein HY. Determination of diosmin in pharmaceutical formulations using Fourier transform infrared spectrophotometry. Saudi Pharm J. 2009;17(4):303-6. doi: 10.1016/j.jsps.2009.10.008.

7. Russo R, Chandradhara D, De Tommasi N. Comparative bioavailability of two diosmin formulations after oral administration to healthy volunteers. Molecules. 2018;23(9). doi: 10.3390/ molecules23092174.

8. Mauludin R, Müller R. Physicochemical properties of hesperidin nanocrystal. J Pharm Pharm Sci. 2013;5(3): 954-60. doi: 10.1016/j.ejps.2008.12.002.

9. Maggioli A. Chronic venous disorders: pharmacological and clinical aspects of micronized purified flavonoid fraction. Phlebolymphology. 2016;23(2):82-91. doi: 10.1053/j. semvascsurg.2015.06.001.

10. Srilatha D, Nasare M, Nagasandhya B, Prasad V, Diwan P. Development and validation of UV spectrophotometric method for simultaneous estimation of hesperidin and diosmin in the pharmaceutical dosage form. ISRN Spectroscopy.2013;1-4. doi: $10.1155 / 2013 / 534830$.
11. Aboul-Enein HY. A spectrophotometric method for diosmin determination. Open Chem Biomed Meth J. 2010;3(1):123-7.

12. Silvestro L, Tarcomnicu I, Dulea C, Attili NRBN, Ciuca V, Peru D, et al. Confirmation of diosmetin 3-O-glucuronide as major metabolite of diosmin in humans, using micro-liquid-chromatographymass spectrometry and ion mobility mass spectrometry. Anal Bioanal Chem. 2013;405(25):8295310. doi: 10.1007/s00216-013-7237-y.

13. Iordachescu A, Silvestro L, Rizea Savu S, Tarcomnicu I, Moise A. Diosmetin pharmacokinetic following diosmin oral administration in man; A new study on an old product with controversial pharmacokinetic findings in the past. J Bioequiv Availab. 2012;4(3). doi: 10.4172/0975-0851. S1.02

14. Ai F, Ma Y, Wang J, Li Y. Preparation, physicochemical characterization and in - vitro dissolution studies of diosmin-cyclodextrin inclusion complexes. Iran J Pharm Res. 2014 Fall;13(4):1115-23.

15. Bano S, Javed K, Ahmad S, Rathish IG, Singh S, Chaitanya M, et al. Synthesis of some novel chalcones, flavanones and flavones and evaluation of their anti-inflammatory activity. Eur J Med Chem. 2013;65:51-9. doi: 10.1016/j.ejmech.2013.04.056.

16. Lokhande PD, Sakate SS, Taksande KN, Navghare B. Dimethylsulfoxide-iodine catalysed deprotection of 2'-allyloxychalcones: synthesis of flavones. Tetrahedron Lett. 2005;46(9):1573-4. doi: 10.1016/j. tetlet.2004.12.041.

17. Nawghare BR, Gaikwad SV, Raheem A, Lokhande PD. Iodine catalyzed cascade synthesis of flavone derivatives from 2'-allyloxy- $\alpha$, $\beta$-dibromochalcones. J Chil Chem Soc. 2013;59(1), 2284-6. doi: 10.4067/S0717-97072014000100009.

18. Matsuura S, Iinuma M, Ishikawa K, Kagei K. Synthetic studies of the flavone derivatives. V. The use of DDQ in the dehydrogenation of flavanones. (I). Chem Pharm Bull. 1978;26(1):305-06. doi: 10.1248/ cpb.26.305.

19. Council of Europe. European Pharmacopoeia 8th ed. Strasbourg: Council of Europe; Diosmin. 2008; 2072-73.

20. Sher E, Codignola A, Biancardi E, Cova D, Clementi F. Amine uptake inhibition by diosmin and diosmetin in human neuronal and neuroendocrine cell lines. Pharmacol Res. 1992;26(4):395-402. 
21. Beiler JM, Martin GJ. Inhibition of hyaluronidase action by derivatives of hesperidin. J Biol Chem. 1948;174:31-35.

22. Leopoldini M, Russo N, Toscano M. The molecular basis of working mechanism of natural polyphenolic antioxidants. Food Chem. 2011;125(2):288-306. doi: 10.1016/j.foodchem.2010.08.012.

23. Guerrero L, Castillo J, Quiñones M, Garcia-Vallvé S, Arola L, Pujadas G, et al. Inhibition of angiotensin-converting enzyme activity by flavonoids: structure-activity relationship studies. PLoS ONE. 2012;7(11): e49493. doi: 10.1371/journal. pone.0049493.
24. Park HJ, Kim MJ, Ha E, Chung JH. Apoptotic effect of hesperidin through caspase 3 activation in human colon cancer cells, SNU-C4. Phytomedicine. 2008;15(1-2):147-51. doi: 10.1016/j. phymed.2007.07.061.

25. Iranshahi M, Rezaee R, Parhiz H, Roohbakhsh A, Soltani F. Protective effects of flavonoids against microbes and toxins: The cases of hesperidin and hesperetin. Life Sci. 2015;137:125-32. doi: 10.1016/j. lfs.2015.07.014

26. Kaur H, Kaur G. A critical appraisal of solubility enhancement techniques of polyphenols. J Pharm. 2014;2014:1-14. doi: 10.1155/2014/180845. 